\title{
Lactate Metabolism in Normal and Growth-Retarded Human Fetuses
}

\author{
ANNA MARIA MARCONI, IRENE CETIN, ENRICO FERRAZZI, MARIA M. FERRARI, \\ GIORGIO PARDI, AND FREDERICK C. BATTAGLIA \\ Department of Obstetrics and Gynecology, University of Milano, Ospedale San Paolo, Milano, Italy \\ [A.M.M., I.C., E.F., M.M.F., G.P.] and Division of Perinatal Medicine, Department of Pediatrics, \\ University of Colorado School of Medicine, Denver, Colorado 80262 [F.C.B.]
}

\begin{abstract}
Lactate concentration and oxygen content were measured in 21 normal (AGA) and 34 intrauterine growth-retarded (IUGR) infants at the time of elective cesarean section. Maternal lactate and umbilical arterial and venous lactate concentrations were significantly higher in IUGR infants compared with AGA infants. However, when IUGR patients were subdivided according to pulsatility index (PI) measurements of the umbilical artery, no differences were detected between AGA and IUGR patients with $\mathrm{PI}<4 \mathrm{SD}$, whereas IUGR patients with $\mathrm{PI}>4 \mathrm{SD}$ had higher lactate concentrations in maternal arterial blood and umbilical arterial and venous blood from both other groups. There was a significant inverse linear relationship between umbilical arterial lactate concentration and umbilical venoarterial differences for both lactate concentrations and for lactate/oxygen quotients. These relationships were significantly different in IUGR fetuses with PI $>4$ SD compared with AGA and IUGR fetuses with PI $<4$ SD. AGA and IUGR fetuses with PI <4 SD have arterial lactate concentrations $<2 \mathrm{mM}$ even at low oxygen concentrations $\left(\mathrm{O}_{2}\right.$ content $<2 \mathrm{mM}, \mathrm{O}_{2}$ saturations $\left.<20 \%\right)$. At comparable levels of oxygenation, IUGR fetuses with PI $>4$ SD have a marked lactacidemia. The data suggest that coupling Doppler assessment of flow velocimetry with biochemical analyses of fetal blood can be useful in identifying a subset of IUGR human fetuses at risk of intrauterine hypoxia. (Pediatr Res 28: 652-656, 1990)
\end{abstract}

\section{Abbreviations}

AGA, appropriate for gestational age

$\mathrm{AV}$, arteriovenous

IUGR, intrauterine growth retardation

MA, maternal arterial blood

PI, pulsatility index

ua, umbilical arterial blood

uv, umbilical venous blood

The subject of fetal lactate metabolism has been of considerable interest for many years both in clinical obstetrics and in perinatal physiology (1-4). At delivery, lactate concentrations have been measured in cord blood to determine the presence and the degree of fetal metabolic acidosis after intrapartum

Received July 10, 1990; accepted August 8, 1990.

Correspondence and reprint requests: Frederick C. Battaglia, M.D., Division of Perinatal Medicine, Department of Pediatrics, University of Colorado Health Sciences Center, 4200 East Ninth Avenue, Box B-199, Denver, CO 80262.

Supported by Grant No. 85.00483.56 from the Italian National Research Council (C.N.R.), NIH P-50 Center Grant No. HD-20761, NIH Program Grant No. HD-00781, and NATO Grant No. 0191/88. asphyxia. Thus, clinical studies have focused on the stressed fetus and have attempted to correlate lactate concentration with the length of labor (3) and/or the presence of late decelerations (5).

More recently, studies in animals have shown that lactate is produced by the placenta $(6-10)$ under aerobic conditions and that the fetus is a net lactate consumer. Lactate production under aerobic conditions has also been demonstrated for the perfused human placenta $(11-13)$. In contrast to the data obtained in chronically catheterized animals, most clinical studies have found the umbilical arterial concentration to be higher than the umbilical venous concentrations $(3,4,14)$. Whether this is a reflection of the fact that these data were collected at the time of cesarean section or whether a net lactate production by the fetus is a normal characteristic of fetal development cannot be answered at this time.

Recently, this topic has received renewed interest with the advent of techniques for the sampling of fetal blood during pregnancy (15) and for the evaluation of Doppler waveforms on fetal vessels (16). The correlation of biophysical indices of vascular impedance in the umbilical circulation with measurements of fetal biochemical parameters in pregnancies complicated by IUGR has shown that as velocimetry data suggest an increase in umbilical vascular impedance, the biochemical indices of lactate concentration and acid-base balance become suggestive of a fetal metabolic acidosis $(17,18)$. However, with percutaneous umbilical blood sampling, data from only one umbilical vessel is obtained. It is not possible to measure AV concentration differences as it is at the time of delivery.

The purposes of our study were 2-fold: 1 ) to determine whether differences in lactate concentration relationships exist between AGA and IUGR fetuses reflecting differences in placental clearance and fetal lactate metabolism, and 2) to determine whether combining Doppler velocimetry and fetal lactate concentration measurements can identify a subset of IUGR fetuses at increased risk for hypoxia.

\section{MATERIALS AND METHODS}

We studied 55 patients undergoing elective cesarean section: the clinical indications for cesarean section are given in Table 1. Twenty-one had uneventful pregnancies and delivered infants whose birth weights were AGA, that is, within the 10th and 90th percentiles referenced to Italian birth weight-gestational age standards (19). In the remaining 34 cases, pregnancy was complicated by IUGR. The diagnosis was assessed before delivery from the gestational age estimated from the last menstrual period and serial ultrasound examinations begun before $20 \mathrm{wk}$ of pregnancy. In all cases, fetal growth retardation was confirmed at birth (19). No chromosomal abnormalities and/or malformations were present. All birth weights were below the 10 th percentile (five between the 10 th and 5 th percentiles, nine between the 5 th and 2 nd percentiles, and 20 below the 2 nd percentile). 
Table 1. Indications for cesarean section

\begin{tabular}{lcc}
\hline & \multicolumn{2}{c}{$\begin{array}{c}\text { Gestational } \\
\text { age } \\
(\mathrm{wk})\end{array}$} \\
\hline Normally grown fetuses & $n$ & \\
$\quad$ Breech presentation & 4 & $37-39$ \\
Previous cesarean section & 16 & $37-39$ \\
$\quad$ Breast cancer & 1 & 35 \\
IUGR fetuses & & \\
IUGR + fetal distress & 15 & $28-37$ \\
IUGR as sole indication & 19 & $34-39$ \\
\hline
\end{tabular}

Thus, 29 of the 34 patients were $<2$ SD below the mean birth weight for their gestational ages. In all pregnancies, a Doppler examination of flow velocity waveforms in the umbilical vessels was performed within $2 \mathrm{~d}$ of delivery and the PI of the umbilical artery measured (Ultramark 5, ATL/Kontron, Milano, Italy); Doppler filters were settled at $50 \mathrm{~Hz}$. The PI was calculated according to the geometrical Gosling formula (20; see Appendix). It reflects changes in pulsatility and peripheral resistance and thus provides an indirect assessment of vascular impedance. As reference values, we have used those obtained in our laboratory on a cross-sectional study of 440 normal pregnancies (21). Figure 1 presents the PI measurements in all cases plotted with the mean \pm SD of the normal population. All AGA fetuses showed PI values within the normal range for their gestational age. In IUGR fetuses, 10 fetuses showed normal PI values, eight showed moderately increased PI values (2-4 SD above the mean value), and in 16 pregnancies the PI was markedly increased ( $>4$ SD above the mean value).

In all cases, the cesarean section was performed under general anesthesia; none of the mothers had entered labor. The surgical procedure was performed under general anesthesia and the patients were ventilated with nitrous oxide with a concentration of $60 \%$ nitrous oxide and $40 \%$ oxygen. Maternal blood pressure was carefully monitored and no significant hypotensive episodes were recorded. Immediately after fetal extraction, the umbilical cord was doubly clamped and blood was withdrawn from the umbilical artery and vein. Maternal radial arterial blood was collected simultaneously.

Fetal and maternal blood were collected into heparinized syringes that were immediately sealed and stored on ice. Lactate concentration was measured in duplicate on a Yellow Springs analyzer (Yellow Springs Instrument Co., Yellow Springs, OH; model $23 \mathrm{~L}$ ) within 5 min of cord sampling; respiratory gases were determined on a Radiometer ABL 330 analyzer (Radiometer America, Inc., Westlake, $\mathrm{OH})$. $\mathrm{Hb}$ concentration and oxygen saturation were measured in duplicate on a Radiometer OSM-3

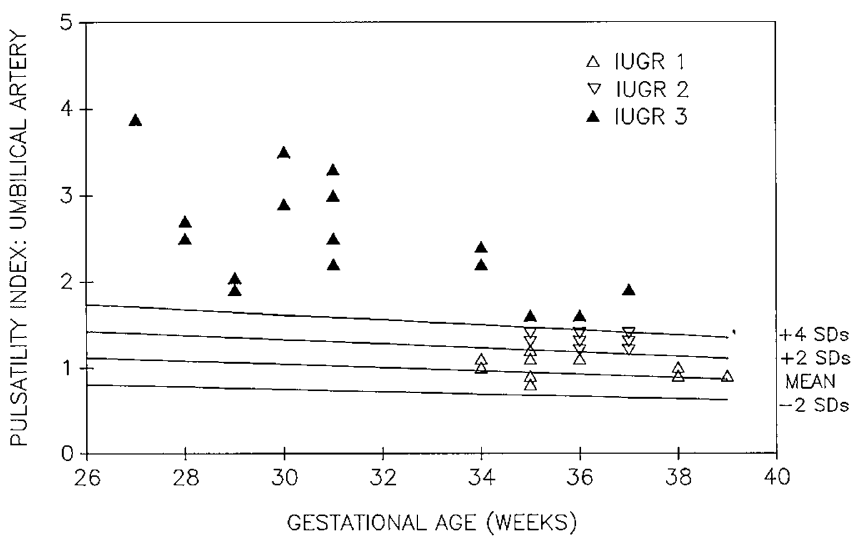

Fig. 1. PI of the umbilical artery in IUGR fetuses according to gestational age $(\Delta$ : normal PI; $\nabla: \mathrm{PI}>2<4 \mathrm{SD} ; \mathbf{\Delta}$ : PI $>4 \mathrm{SD})$. The mean and \pm 2 SD and 4 SD are presented for 440 normal pregnancies presented in a previous study of this population (21). oximeter; oxygen content was calculated from these values according to the formula:

Oxygen content (mM)

$$
=\mathrm{Hb}(\mathrm{g} / \mathrm{L}) \times \text { oxygen saturation } \times 0.05982
$$

All biochemical analyses were completed in $10 \mathrm{~min}$.

To quantitate fetal net utilization of lactate relative to oxygen uptake, lactate/oxygen quotients (LOQ) were calculated as follows:

$\mathrm{LOQ}=$ Lactate $\mathrm{AV}$ difference $(\mathrm{mM})$

$$
\times 3 \text { / oxygen AV difference }(\mathrm{mM})
$$

Metabolic quotients represent a ratio of two AV differences; that of the substrate, lactate, divided by that of $\mathrm{O}_{2}$. The lactate differences are multiplied by the number of mol of $\mathrm{O}_{2}$ required to completely oxidize $1 \mathrm{~mol}$ of lactate. The algebraic sum of the metabolic quotients for all relevant substrates across an organ would be equal to one in the absence of any net carbon accretion. For any single substance including lactate, the metabolic quotient may be positive or negative depending upon whether the AV difference across the organ is positive or negative.

All the results are expressed as mean \pm SEM. The paired $t$ test was used to calculate the significance of the differences between maternal and fetal lactate concentrations. The significances of the difference between AGA and IUGR as well as between the three subsets of IUGR patients were calculated with an unpaired $t$ test. Regression analyses were carried out by the least squares method. Differences between slopes were tested using a multiple linear regression analysis.

\section{RESULTS}

Lactate concentrations. The mean umbilical arterial and venous lactate concentrations, oxygen contents, umbilical venoarterial lactate and oxygen concentration differences, and lactate/ oxygen quotients (and coefficients of $\mathrm{O}_{2}$ extraction) in AGA and IUGR infants are reported in Table 2 . There is a range of gestational age among these pregnancies. However, we have previously demonstrated that lactate concentration and oxygen content do not vary from 20 wk until term (22). Table 2 also presents the mean lactate concentrations in MA and the umbilical arterial-maternal arterial lactate concentration differences. Maternal arterial lactate concentration was significantly higher $(p<0.01)$ in growth-retarded compared with normally grown fetuses. Lactate concentration was significantly higher in uv and ua than in MA (for AGA pregnancies: uv versus MA, $p<0.001$; ua versus MA, $p<0.001$; for IUGR pregnancies: uv versus MA, $p<0.001$; ua versus MA, $p<0.001$ ). The mean umbilical arterial and venous lactate concentrations were significantly higher in IUGR compared with AGA pregnancies. No differences were detected between the two groups with regard to the umbilical venoarterial difference, the lactate/oxygen quotient and the umbilical arterial-maternal arterial lactate concentration differences.

Umbilical venous lactate concentration was higher than arterial in six of 21 AGA and 12 of 34 IUGR fetuses.

$P I$ and lactate concentrations. Figure 2 presents the same variables presented in Table 2 but subdivides IUGR fetuses into two groups according to their PI measurements $(>$ or $<4$ SD) from the mean value. The data on AGA fetuses are also shown for comparison. Figure 2 illustrates that when IUGR pregnancies were subdivided based upon velocimetry data, they were also distinguishable based upon the presence or absence of fetal lactacidemia. It is clear that the umbilical arterial and venous lactate concentrations and the umbilical arterial-maternal arterial concentration differences were significantly higher in growthretarded fetuses with $\mathrm{PI}>4 \mathrm{SD}$ compared with both IUGR infants with PI $<4 \mathrm{SD}$ and AGA infants. It is worth noting that no significant differences were detected between IUGR fetuses with $\mathrm{PI}<4 \mathrm{SD}$ and AGA fetuses. There was also a significant 
Table 2. Lactate concentrations and oxygen contents in AGA and IUGR fetuses

\begin{tabular}{|c|c|c|c|c|c|c|}
\hline & \multicolumn{3}{|c|}{ Lactate concentration (mM) } & \multicolumn{3}{|c|}{ Oxygen content (mM) } \\
\hline & $\mathrm{AGA}$ & $p$ & IUGR & AGA & $p$ & IUGR \\
\hline Maternal artery (mM) & $0.68 \pm 0.07$ & 0.01 & $0.91 \pm 0.05$ & & & \\
\hline Umbilical artery (mM) & $1.15 \pm 0.08$ & 0.005 & $1.85 \pm 0.19$ & $2.20 \pm 0.25$ & NS & $1.84 \pm 0.24$ \\
\hline Umbilical difference (mM) & $-0.16 \pm 0.05$ & NS & $-0.13 \pm 0.04$ & $3.24 \pm 0.16$ & NS & $2.81 \pm 0.12$ \\
\hline Umbilical lactate/oxygen quotient & $-0.16 \pm 0.05$ & NS & $-0.14 \pm 0.05$ & & & \\
\hline Umbilical artery-maternal artery (mM) & $0.44 \pm 0.07$ & NS & $0.90 \pm 0.20$ & & & \\
\hline
\end{tabular}

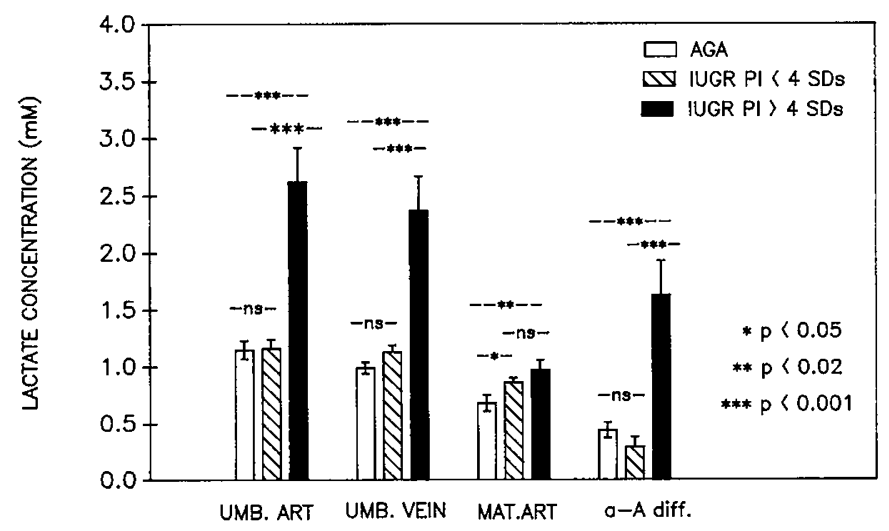

Fig. 2. Comparison of maternal and fetal lactate concentrations in AGA and IUGR fetuses with PI of the umbilical artery within and $>4$ $\mathrm{SD}$.

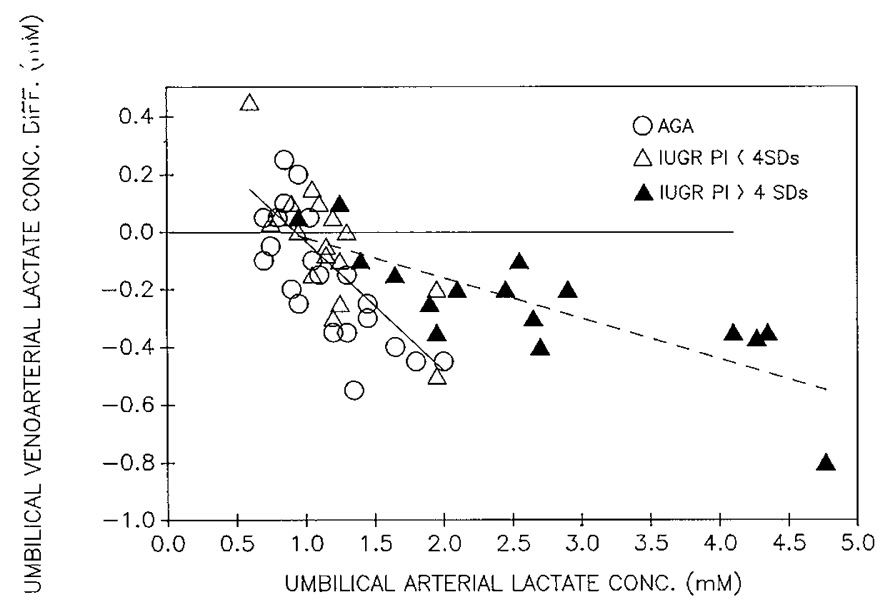

Fig. 3. Umbilical venoarterial lactate concentration difference $v s$ umbilical arterial lactate concentration in normally grown fetuses and in growth-retarded fetuses with PI within $4 \mathrm{SD}$ and $>4 \mathrm{SD}$. Because no differences were detected between AGA and IUGR PI $<4$ SD in this relationship, a common regression line was calculated. AGA + IUGR (PI < 4 SD): $\mathrm{v}-\mathrm{a}=0.42-0.46, \mathrm{a}, r=0.72, p<0.001$; and IUGR $(\mathrm{PI}>4$ $\mathrm{SD}): \mathrm{v}-\mathrm{a}=0.08-0.13 \mathrm{a}, r=0.80, p<0.001$ where $\mathrm{v}-\mathrm{a}=$ umbilical venoarterial lactate concentration difference $(\mathrm{mM})$ and $\mathrm{a}=$ umbilical arterial lactate concentration (mM).

and progressive increase of the maternal arterial lactate concentration, which was higher in IUGR fetuses with PI $<4$ SD and highest in IUGR fetuses with PI $>4 \mathrm{SD}$, compared with AGA pregnancies.

No differences were detected between AGA and IUGR fetuses with $\mathrm{PI}<4 \mathrm{SD}$ in the relationships between umbilical lactate concentration differences and lactate/oxygen quotients versus umbilical arterial lactate concentrations (Figures 3 and 4). On the contrary, the regression analysis for the lactate/oxygen quo-

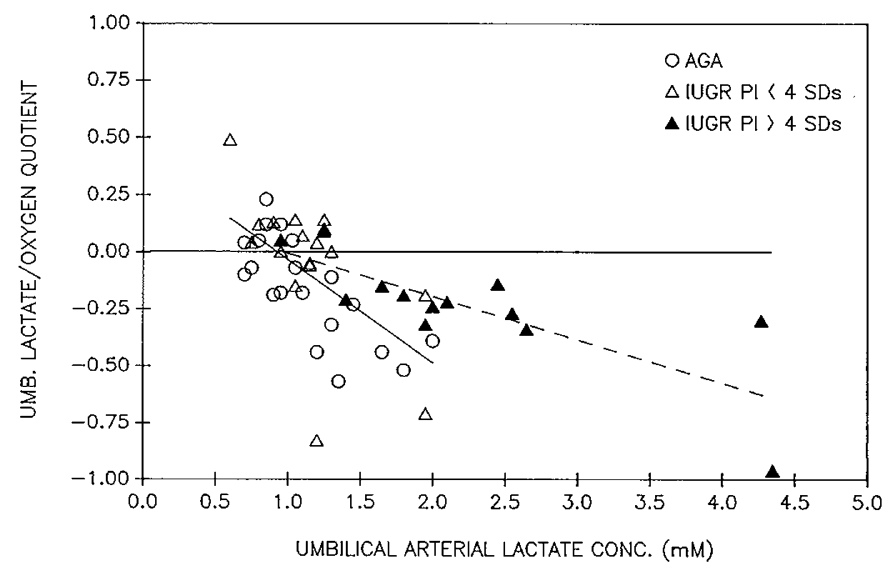

Fig. 4. Umbilical lactate/oxygen quotient $v s$ umbilical arterial lactate concentration in normally grown and growth-retarded fetuses. AGA + IUGR (PI $<4 \mathrm{SD}$ ): $\mathrm{L} / \mathrm{O}_{2}=0.46-0.50 \mathrm{a}, r=0.66, p<0.001$; and IUGR (PI $>4$ SD): $\mathrm{L} / \mathrm{O}_{2}=0.02-0.13$ a, $r=0.77, p<0.002$ where $\mathrm{L} / \mathrm{O}_{2}=$ umbilical lactate $/ \mathrm{O}_{2}$ quotient $\mathrm{a}=$ umbilical arterial lactate concentration $(\mathrm{mM})$.

tient versus lactate concentration for IUGR fetuses with PI $>4$ $\mathrm{SD}$ was significantly different from both other groups, both in elevation $(p<0.008)$ and in slope $(p<0.001)$.

If one pools the data for AGA fetuses and IUGR fetuses with PI less than $4 \mathrm{SD}$ to compare this group to the IUGR fetuses with PI greater than $4 \mathrm{SD}$, the following equations are obtained. For umbilical lactate arterial venous differences (v-a): Pooled group, $(v-a)=0.42-0.461(a)$; and IUGR $(>4),(v-a)=0.08-$ 0.128 (a) where (a) is umbilical arterial lactate concentration. For umbilical lactate quotient: Pooled: quotient $=0.46-0.50$ (a) IUGR (>4): quotient $=0.02-0.13(\mathrm{a})$.

The differences between slopes for the pooled versus IUGR fetuses are highly significant ( $p<0.001$ for both comparisons).

Oxygen concentrations and lactate concentrations. Figures $5 \mathrm{~A}$ and $B$ presents the relationship between umbilical arterial lactate concentration on the one hand and umbilical arterial oxygen content (Fig. 5A) and umbilical arterial oxygen saturation (Fig. $5 B$ ) in AGA and IUGR fetuses. There is a significant relationship between lactate concentration and either arterial oxygen content or oxygen saturation: as oxygenation decreases, lactate concentration increases. However, in growth-retarded fetuses with PI $>4 \mathrm{SD}$, this relationship is characterized by much higher lactate concentrations at the same level of fetal oxygenation, whereas in AGA fetuses and in IUGR fetuses with PI $<4 \mathrm{SD}$, there is a linear relationship with little increase in lactate concentration over a wide range of oxygen contents and saturation. In AGA and IUGR fetuses with PI $<4 \mathrm{SD}$, even at arterial oxygen content lower than $2 \mathrm{mM}$, umbilical arterial lactate concentration did not exceed $2 \mathrm{mM}$.

\section{DISCUSSION}

The first aim of our study was to determine whether differences in lactate concentrations in umbilical vessels exist between nor- 

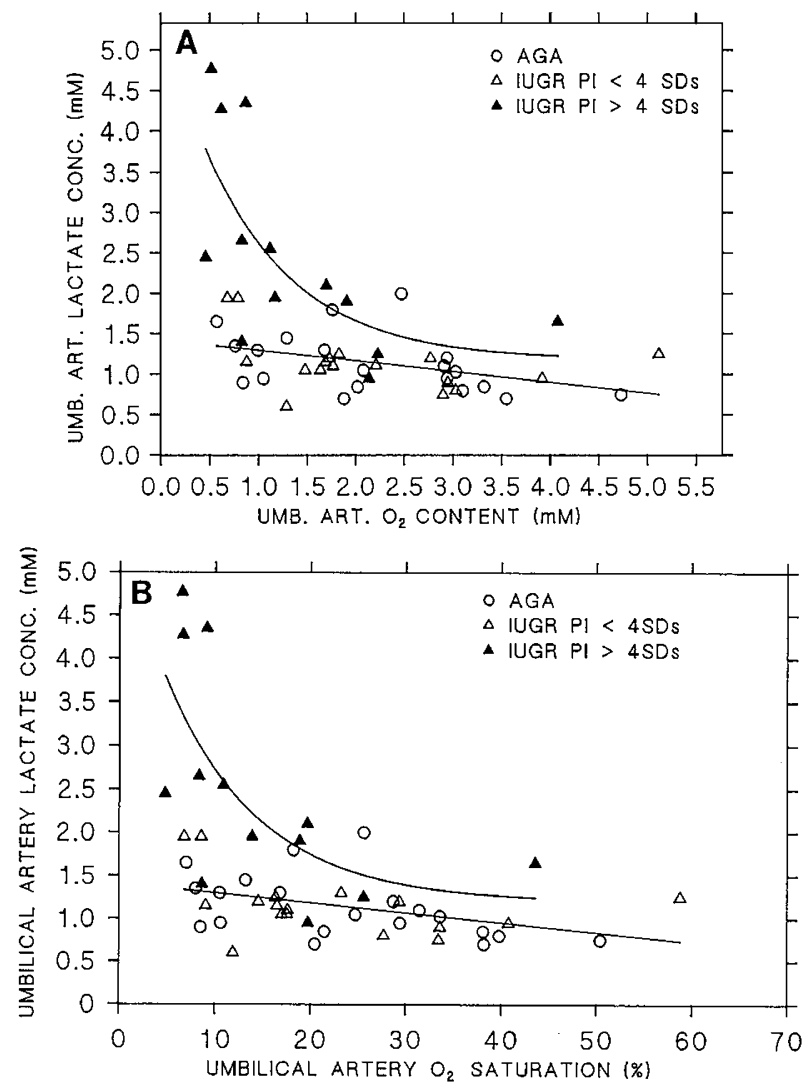

Fig. 5. $A$, Umbilical arterial lactate concentration $v s$ umbilical arterial oxygen content in normally grown fetuses and growth-retarded fetuses. AGA + IUGR (PI < 4 SD): a lactate $=1.43-0.13$ a $\mathrm{O}_{2} r=0.41, p<$ $0.001 ;$ and IUGR $(\mathrm{PI}>4 \mathrm{SD}):$ a lactate $=5.78-4.56\left(1-\mathrm{e}^{-1.19 \mathrm{aO}_{2}}\right)$ where $\mathrm{aO}_{2}=$ umbilical arterial $\mathrm{O}_{2}$ content $(\mathrm{mM})$ and a lactate $=$ umbilical arterial lactate concentration. $B$, Umbilical arterial lactate concentration vs umbilical arterial oxygen saturation in normally grown fetuses and growth-retarded fetuses. AGA + IUGR (PI $<4$ SD): a lactate $=1.41-$ 0.01 (a Sat), $r=0.41, p<0.001$; and IUGR (PI $>4$ SD): a lactate $=$ 5.45-4.25 $\left(1-\mathrm{e}^{-0.1 \text { aSat }}\right)$ where a lactate $=$ umbilical arterial lactate concentration and a Sat $=$ umbilical arterial $\mathrm{O}_{2}$ saturation $(\%)$.

mally grown and growth-retarded human fetuses at the time of cesarean section. If we consider IUGR fetuses as a homogeneous population, that is fetuses whose birth weights are below the 10th percentile, our data show that indeed lactate concentrations are significantly higher in these fetuses. This is not surprising inasmuch as growth retardation has always been considered a clinical situation most likely subject to develop intrauterine hypoxia. However, recent studies performed on IUGR fetuses sampled in utero by cordocentesis have permitted a more thorough description of their intrauterine environment: these studies have shown that the hematologic and biochemical values of these fetuses do not always differ from normal control values (15-23). Thus, IUGR itself is not a condition invariably associated with fetal hypoxia. Therefore, from a clinical viewpoint, it becomes important to distinguish, as early as possible, those IUGR pregnancies at high risk of developing intrauterine fetal hypoxia.

The results of our study suggest that the first factor that should be taken into account is gestational age. It is clear from our data (Fig. 6) that growth retardation severe enough to require delivery before $32 \mathrm{wk}$ gestation is frequently associated with abnormal PI measurements and that most of these fetuses present lactic acidemia. These features are rarely present in fetuses delivered after 34 wk of gestation, presumably because IUGR of late onset usually represents less disturbance of the intrauterine environment.

IUGR is a diagnosis that encompasses a very heterogeneous

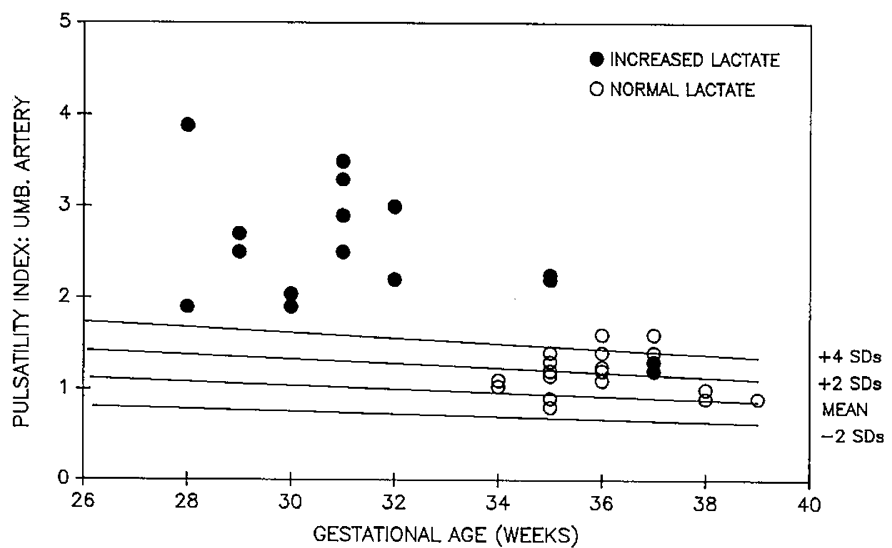

Fig. 6. PI measurements $v s$ gestational age for all IUGR fetuses. IUGR fetuses with umbilical arterial lactate concentration $>2$ SD of AGA fetuses. $\mathrm{O}$, IUGR fetuses with lactate concentration within $\pm 2 \mathrm{SD}$ of the mean for AGA fetuses.

group of patients both in terms of potential causal factors and in terms of the nature and severity of the morbidity in the fetus. The results of our study clearly demonstrate that IUGR fetuses can be subdivided into at least two subgroups according to PI measurements upon the umbilical artery. An increase in the PI should provide a reliable, albeit indirect, index of increased vascular impedance in the umbilical circulation and, thus, an indication of reduced placental perfusion.

IUGR fetuses with PI $>4$ SD exhibited significantly higher lactate concentrations than IUGR fetuses with PI $<4 \mathrm{SD}$. The differences in lactate metabolism between IUGR fetuses with PI $<4$ SD and three with PI $>4$ SD also extends to the analysis of both umbilical lactate concentration differences and lactate/ oxygen quotients versus umbilical arterial lactate concentrations. Despite the presence of significantly higher umbilical arterial lactate concentrations, IUGR fetuses with PI $>4 \mathrm{SD}$ tend to maintain lower umbilical lactate differences and lactate/oxygen quotients for any given lactate concentration.

Velocimetry measurements are still in a stage of clinical evaluation. The subdivision into SD is arbitrary. In this relatively small population, one could have identified this subset of patients as effectively by selecting a PI value of 1.8 , above which all IUGR fetuses were found to have a lacticacidemia. However, that patients with velocimetry measurements $>2 \mathrm{SD}$ but $<4 \mathrm{SD}$ were not significantly different from normal patients with respect to the presence or absence of a lacticacidemia suggests that only marked changes in PI are of clinical significance in this regard.

Similarly, the same subdivision of IUGR fetuses by PI measurements greater than or less than $4 \mathrm{SD}$ identifies infants who differ in the relationships of umbilical arterial lactate concentrations versus relationships of umbilical arterial lactate concentrations versus umbilical arterial oxygen content or saturations. Among growth-retarded fetuses with PI within $4 \mathrm{SD}$, arterial lactate concentrations increased only slightly even when arterial oxygen content was as low as $1 \mathrm{mM}$. On the contrary, in growthretarded fetuses with $\mathrm{PI}>4 \mathrm{SD}$, lactate concentrations were not only elevated but increased sharply at comparably low arterial oxygen contents.

A possible explanation for the differences in lactate metabolism in the two groups of growth-retarded fetuses may be a combination of the following. One factor may be a decreased placental permeability (24): a number of histologic changes have been described in IUGR placentas that could determine a decreased surface area. In addition, a reduction in umbilical blood flow may further impact upon the efflux of substrate from the umbilical circulation; that is, it may reduce placental lactate clearance. Consistent with this hypothesis is the observation of significantly higher lactate concentration differences across the placenta in IUGR fetuses with PI $>4$ SD compared with IUGR 
fetuses with PI $<4$ SD, again suggesting a decreased placental clearance in these pregnancies.

In a recent paper, we reported the correlation between biochemical monitoring versus umbilical flow velocity waveforms in growth-retarded fetuses sampled in utero by cordocentesis (17). A curvilinear relationship was found between the PI of the umbilical artery and lactate concentrations in the umbilical vein such that at PI $>1.5$, lactate concentration in uv increases sharply. Our present results obtained at cesarean section are in good agreement with the cordocentesis data. In addition, we now report that PI measurements during pregnancy can help identify subsets of IUGR fetuses who differ biochemically as well.

A striking finding in our present study is that no significant biochemical differences were present between normally grown fetuses and IUGR fetuses whose PI were normal or slightly increased. Recent studies in animals have demonstrated that the relationship of uterine and umbilical blood flows to placental transport of oxygen and glucose is nonlinear; that is, either uterine or umbilical blood flow can be reduced with minimal impact upon placental transport of oxygen or glucose until a critical level is reached. Further reduction is accompanied by a sharp decrease in placental oxygen and glucose transport $(25$, 26). Therefore, it is not surprising that most fetuses with PI $<4$ SD exhibited normal umbilical arterial lactate levels.

In this study, six of $21 \mathrm{AGA}$ and 12 of 34 IUGR fetuses showed umbilical differences in lactate concentration and lactate/oxygen quotient that were positive. This observation confirms and extends those previously reported by other authors (3, 4,14 ) and suggests that under some conditions the human fetuses can be a net lactate consumer. Further support for this hypothesis stems from the fact that lactate concentrations tend to be lower in blood obtained at cordocentesis versus the data collected at the time of delivery. Because a positive venoarterial lactate concentration difference is only found in association with low arterial lactate concentrations, it is not surprising that most data collected at the time of delivery tends to show a positive arterial venous difference.

The high variance in umbilical lactate concentration differences that we have found in human studies is not found in animal studies carried out under chronic steady state conditions. We believe this is due to the fact that in human pregnancies, simultaneous uv and ua samples can be obtained only under non-steady state conditions (i.e. at the time of cesarean section or vaginal delivery).

Finally, we were surprised to find that lactate concentrations were significantly higher and progressively increased in mothers of IUGR fetuses compared with mothers of AGA fetuses. Lactate is a key gluconeogenic precursor. In that regard, it is interesting that we have found higher plasma alanine concentrations in mothers of IUGR babies compared with mothers of AGA babies (27). Thus, two compounds that feed into the pyruvate pool, alanine, and lactate, are elevated in these mothers. These observations suggest the presence of major maternal metabolic differences in pregnancies complicated by IUGR.

\section{REFERENCES}

1. Eastman NY, McLane CM 1931 Fetal blood studies. II. The lactic acid content of umbilical cord blood under various conditions. Bull Johns Hopkins Hosp 48:261-268

2. Derom R 1964 Anaerobic metabolism in the human fetus. Am J Obstet Gynecol 89:241-251

3. Stembera ZK, Hodr J 1966 I. The relationship between the blood levels of glucose, lactic acid and pyruvic acid in the mother and in both umbilical vessels of the healthy fetus. Biol Neonate 10:227-238

4. Stembera ZK, Hodr J 1966 Il. Mutual relationships between the levels of glucose, pyruvic acid and lactic acid in the blood of the mother and of both umbilical vessels in hypoxic fetuses. Biol Neonate 10:303-315

5. Low JA, Pancham SR, Worthington D, Boston RW 1975 The acid-base and biochemical characteristics of intrapartum fetal asphyxia. Am J Obstet Gynecol 121:446-451

6. Burd LI, Jones Jr MD, Simmons MA, Makowski EL, Meschia G, Battaglia FC
1975 Placental production and foetal utilization of lactate and pyruvate. Nature 254:210-211

7. Charlton V, Creasy RK 1976 Lactate and pyruvate as fetal metabolic substrates. Pediatr Res 10:231-234

8. Comline RS, Silver M 1976 Some aspects of foetal and utero-placental metabolism in cows with indwelling umbilical and uterine vascular catheters. $\mathbf{J}$ Physiol (Lond) 260:571-586

9. Battaglia FC, Meschia G 1986 An Introduction to Fetal Physiology. Academic Press Inc, Orlando, FL

10. Sparks JW, Hay Jr WW, Bond D, Meschia G, Battaglia FC 1982 Simultaneous measurements of lactate turnover rate and umbilical lactate uptake in the fetal lamb. J Clin Invest 70:179-192

11. Holzman IR, Phillips AF, Battaglia FC 1979 Glucose metabolism, lactate and ammonia production by the human placenta in vitro. Pediatr Res 13:117120

12. Schneider H, Challier JC, Dancis J 1981 Transfer and metabolism of glucose and lactate in the human placenta studied by a perfusion system in vitro. Placenta (suppl 2):129-138

13. Hauguel S, Challier JC, Cedard L, Olive G 1983 Metabolism of the human placenta perfused in vitro. Glucose transfer and utilization, $\mathrm{O}_{2}$ consumption, lactate and ammonia production. Pediatr Res 17:729-732

14. Schneider H, Danko J, Huch R, Huch A 1984 Homeostasis of fetal lactate metabolism in late pregnancy and the changes during labor and delivery. Eur J Obstet Gynecol Reprod Biol 17:183-192

15. Pardi G, Buscaglia M, Ferrazzi E, Bozzetti P, Marconi AM, Cetin I, Battaglia FC, Makowski EL 1987 Cord sampling for the evaluation of oxygenation and acid base balance in growth retarded human fetuses. Am J Obstet Gynecol 157:1221-1228

16. Griffin D, Cohen-Overbeek T, Campbell S 1983 Fetal and utero-placental blood flow. Clin Obstet Gynecol 10:565-602

17. Ferrazzi E, Pardi G, Buscaglia M, Marconi AM, Gementi P, Bellotti M, Makowski EL, Battaglia FC 1988 The correlation of biochemical monitoring versus umbilical flow velocity measurements of the human fetus. Am J Obstet Gynecol 159:1081-1087

18. Soothill PW, Nicolaides KH, Bilardo K, Hackett GA, Campbell S 1986 Uteroplacental blood velocity resistance index and umbilical venous $\mathrm{PO}_{2}, \mathrm{PCO}_{2}$, $\mathrm{pH}$, lactate and erythroblast count in growth retarded fetuses. Fetal Ther 1:176-179

19. Bossi A, Caccamo ML, De Scrilli AM, Milani S 1980 Standard del peso del neonato italiano (dalla 32 nd alla 43rd settimana di gestazione). Riv Ital Pediatr (IJP) 6:153-170

20. Gosling RG, King DH 1974 Continuous wave ultrasound as an alternative and complement to x-rays in vascular examinations. In: Reneman RS (ed) Cardiovascular Applications of Ultrasound. North Holland, Amsterdam, pp 266-282

21. Ferrazzi E, Gementi P, Bellotti M, Rodolfi M, Della Peruta S, Barbera A, Pardi G 1990 Doppler velocimetry: critical analysis of umbilical, cerebral and aortic reference values. Eur J Obstet Gynecol Reprod Biol (in press)

22. Bozzetti P, Buscaglia M, Cetin I, Marconi AM, Nicolini U, Pardi G, Makowski EL, Battaglia FC 1987 Respiratory gases, acid-base balance and lactate concentrations of the midterm human fetus. Biol Neonate 51:188-197

23. Cox WL, Daffos F, Forestier F, Descombey D, Aufrant C, Auger MC, Gaschard JC 1988 Physiology and management of intrauterine growth retardation: a biologic approach with fetal blood sampling. Am J Obstet Gynecol 159:3641

24. Cetin I, Marconi AM, Bozzetti P, Makowski EL, Buscaglia M, Battaglia FC, Pardi G 1990 The venous drainage of the pregnant uterus: transplacental respiratory gas differences in normal (AGA) and growth retarded pregnancies. Soc Gynecol Invest 37th Annual Meeting 344:268(abstr)

25. Wilkening $\mathrm{RB}$, Meschia $\mathrm{G} 1985$ Relationship of umbilical venous $\mathrm{PO}_{2}$ to umbilical blood flow. Soc Gynecol Invest 32nd Annual Meeting 298:172(abstr)

26. Wilkening RB, Battaglia FC, Meschia G 1985 The relationship of umbilical glucose uptake to uterine blood flow. J Dev Physiol 7:313-319

27. Cetin I, Corbetta C, Piceni Sereni L, Marconi AM, Bozzetti P, Pardi G, Battaglia FC 1990 Umbilical amino acid concentrations in normal and growth retarded fetuses sampled in utero by cordocentesis. Am J Obstet Gynecol 162:253-261

\section{APPENDIX}

The PI is calculated according to the general formula: ( $\mathrm{V}_{\max }-$ minimum velocity) / mean velocity. The mean velocity of the Doppler shift computed using a map measurer is obtained by dividing the area of flow waveform by the length of the cycle (geometric PI). The mean velocity computed by most automatic analyzers of Doppler waveforms is the sum of the $V_{\max }$ of each sample of the Doppler spectrum analysis divided by the number of samples performed for each cardiac cycle (automatic PI). The correlation between the two methods is defined by the following coefficients: $R^{2}=0.97 ; F=342$. Automatic PI $=-0.1946+$ $1.441^{\text {(geometric } \mathrm{Pl})}-0.9661^{\text {(geometric } \mathrm{Pl})^{2}}$. 